\title{
Delayed Diagnosis of Childhood Brain Tumors in Kenyatta National Hospital
}

\author{
Trizah Tracey John ${ }^{1 *}$, Nimrod Juniahs Mwang'ombe ${ }^{2}$, and Patrick Okoth Akuku ${ }^{1}$ \\ ${ }^{1}$ Department of Surgery, University of Nairobi/ Kenyatta National Hospital, Kenya \\ ${ }^{2}$ School of Medicine, Department of Surgery, Kenyatta University, Kenya
}

*Corresponding authors: Trizah Tracey John, Department of Surgery, University of Nairobi/ Kenyatta National Hospital, Kenya, E-mail: traceyjhn@ yahoo.com

Received: 26 Oct, 2021 | Accepted: 03 Nov, 2021 | Published: 09 Nov, 2021

Citation: John TT, Mwang'ombe NJ, Akuku PO (2021) Delayed Diagnosis of Childhood Brain Tumors in Kenyatta National Hospital. J Neurol Neurobiol 7(2): dx.doi.org/10.16966/2379-7150.179

Copyright: (C) 2021 John TT, et al. This is an open-access article distributed under the terms of the Creative Commons Attribution License, which permits unrestricted use, distribution, and reproduction in any medium, provided the original author and source are credited.

\section{Abstract}

Background: Brain tumors are the second commonest tumors after leukemia and the most common solid tumors in children. Childhood brain tumors are the most common cause of cancer-related deaths in children. Delayed diagnosis is associated with increased morbidity and mortality. Currently, there are no specific studies on this subject in Kenya.

Objective: 1. To establish the pre-diagnostic symptomatic interval of childhood brain tumors. 2. To outline the reasons for delayed diagnosis of childhood brain tumors.

Methods: A cross-sectional study on childhood brain tumors was done. The sample included all patients between 0-12 years presenting with childhood brain tumors during the study period of seven months who met the inclusion criteria. Informed consent was obtained from the caregiver. A questionnaire was used to collect data through an interview, physical examination of the patient, and review of medical records. Questionnaires were coded and data entered into a password-protected database. The data were analyzed using the Statistical Package for Social Sciences by use of descriptive statistics.

Results: Sixty-one children with a brain tumor between the ages of 0-12 years met the inclusion criteria for the study. The pre-diagnostic symptomatic interval ranged from one week to 3 years with a median of 3 months and a mean of $7.7 \pm 9.6$ months. The predominant reason for delayed diagnosis was a lack of health worker awareness at $64 \%$. A total of 25 signs and symptoms were recorded.

Conclusion: The findings outlined the varied presentation of childhood brain tumors. The study demonstrated delayed diagnosis of brain tumors in children.

The main reason for the delayed diagnosis was a lack of awareness by the health worker. Increasing awareness of the variable and complex symptomatology will help in the early diagnosis of childhood brain tumors.

Keywords: Childhood brain tumors; Delayed diagnosis; Kenyatta national hospital

\section{Introduction}

Childhood Brain Tumor (CBT) is used to describe all primary intracranial neoplasms occurring between 0 and 12 years of age. CBT comprises $15-20 \%$ of all brain tumors [1]. Brain tumors are the second most common tumors after leukemia and the most common solid tumors in children [2]. The overall annual incidence of CBT is 1.2-5.14 per 100,000 children [3]. The management of CBT remains a great challenge to clinicians. CBT is the most common cause of cancer-related deaths in children with a five-year survival rate of $75 \%[4]$

Despite the neuroimaging advancement, the timely diagnosis of CBT remains difficult. This is mainly due to the varied presentation and perceived rarity of CBT [5]. The variable presentation is dependent on the type and location of the CBT, as well as the age of the patient.
CBT initially presents like other common but less serious illnesses [6]. This leads to delayed diagnosis which is associated with increased morbidity and mortality at presentation; disabling neurological complications as well as increased cognitive impairment in survivors [2]. Delayed diagnosis has also been associated with psychological distress for patients and caregivers as well as less trust in the health care system by the healthcare seekers [7].

The Pre-diagnostic Symptom Interval (PSI) of an illness is defined as the period between symptom onset and diagnosis. The mean PSI in children with central nervous system tumors reported in studies published over 15 years ranges from 1.8 to 9.8 months and a median of 1 to 3 months [7]. The factors associated with the delayed diagnosis can be grouped into three categories that include; patient and or caregiver factors, health professional factors, and factors related to the 
healthcare system. Early diagnosis of CBT is a fundamental goal to allow for timely treatment when the disease is still at its early stages.

Kenyatta National Hospital is the largest hospital in the country with a bed capacity of about 2000 beds. The hospital is a teaching and referral facility and hosts the largest neurosurgical unit in the country. The hospital receives referrals from the entire nation of Kenya.

\section{Methods}

\section{Study design}

The design was a cross-sectional study.

\section{Study setting}

The study was conducted at the Kenyatta National Hospital at the following units which host patients with childhood brain tumors; neurosurgical clinics, neurosurgical ward $4 \mathrm{c}$, paediatric wards, and accident and emergency neurosurgical areas.

\section{Study population}

The study population comprised all patients between 0-12 years who presented with childhood brain tumors in $\mathrm{KNH}$ and met the inclusion criteria.

\section{Inclusion criteria}

1. Patients between the ages 0-12 years with a brain tumor confirmed either radiologically with CT scan and or MRI of the brain and or histologically.

2. Patients who met criteria [1] above between the ages 7-12 years who assented to participate in the study.

3. Patients who met criteria [1] above and whose caregivers gave informed consent to participate in the study.

\section{Exclusion criteria}

1. Patients/caregivers who declined to give consent/assent or opted out during the study.

2. Patients with a brain tumor who's radiological and or histological diagnosis records were unavailable.

\section{Sample size determination}

The selection method was non-randomized consecutive sampling until the desired sample size of 61 was achieved. CBT constitutes 15$20 \%$ of all brain tumors [1].

Fisher's formula:

$$
n=\frac{Z^{2} x P(1-P)}{E^{2}}
$$

Where,

$$
n=\text { Desired sample size }
$$

$Z=$ value from standard normal distribution corresponding to desired confidence level $(\mathrm{Z}=1.96$ for $95 \% \mathrm{CI})$

$P=$ prevalence/proportion (0.2) [1]

$E=$ Margin of error $( \pm 10 \%)$

Minimum number of patients 61

The minimum sample size determined the duration of the study. The eligible patients were enrolled until the desired sample size was achieved.

\section{Cross-sectional study method}

This was done to provide information on childhood brain tumor presentation, establish the PSI, and determine factors associated with a prolonged symptom interval.

The study period was 2016/2017 (7 months).

\section{Data collection}

This was done by the principal investigator. The caregivers of patients and those patients between the ages of 7-12 years who meet the inclusion criteria were taken through the purpose of the study. The patients' caregivers were asked to make an informed choice to participate in the study by signing the consent form. Those patients between the ages of 7-12 years were asked to assent by signing the assent form.

A questionnaire was used to collect the required data through an interview and physical examination of the patient. Medical records were reviewed and information was recorded in the questionnaire. The data collected included; General information; the patient's age and gender.

Clinical data; the patient and or caregiver were interviewed about symptomatology, the duration of symptoms, and signs of the illness before diagnosis. A neurological examination was carried out to elicit signs of the illness. The patient's clinical notes, radiological images, and histological results were reviewed and the PSI, the reason for late diagnosis as well as the type of tumor were recorded in the questionnaire. The completed questionnaires were submitted to the statistician for analysis.

\section{Data analysis}

Questionnaires were coded and data entered into a passwordprotected database. The data were analyzed using the Statistical Package for Social Scientists (SPSS). Analysis was done using descriptive statistics (mean, median) and summarized using frequencies and percentages. Bar graphs, tables, and pie charts were used for the presentation of results.

\section{Results}

\section{Demographic information}

The demographic distribution of the patients is as shown in table 1. During the study period, a total of 61 patients presented with childhood brain tumors at the Kenyatta National Hospital, of which $38(62.3 \%)$ were male while $23(37.7 \%)$ were female, with a male to female ratio of 1.7:1. Patient ages ranged from as low as 1 month to 12 years with a median age of 8.2 years. The mean age was $7.3 \pm 3.6$ years.

The type of tumor that was most prevalent was craniopharyngioma from $17(27.9 \%)$ of the patients, this was followed by medulloblastoma and pilocytic astrocytoma which had $10(16.4 \%)$ patients each, PNET from 6 (9.8\%) patients, ependymoma from 4 (6.6\%) patients. Brainstem glioma, GBM, meningioma, and thalamic glioma each had $2(3.3 \%)$ patients while choroid plexus papilloma, colloid cyst, optic glioma, pineal gland, SEGA, and tectal glioma had 1 (1.6\%) patient each (Table 2).

\section{Pre-diagnostic symptomatic interval}

Pre-Diagnostic Symptomatic Interval (PSI) ranged from as low as 1 week to 3 years with a median PSI of 3 months. The mean PSI was $7.7 \pm$ 9.6 months. Eleven (18\%) of the patients had a PSI of less than a month while 50 (82\%) had a PSI longer than one month (Table 3). 
On the factors for late diagnosis, the study found out those 39 (64\%) patients had delayed diagnosis due to a lack of awareness by the health worker. $7(11 \%)$ respondents lacked awareness of the illness. $2(3 \%)$ patients lacked finance. One (2\%) patient had unavailability of CT scan for imaging. Twelve (20\%) patients did not have an applicable reason (Figures 1-3)

The study identified 25 signs and symptoms. The top two signs and symptoms were headache from $46(75 \%)$ patients, followed by nausea and vomiting $43(70 \%)$ patients. The other prevalent signs and symptoms exhibited were lethargy and school difficulties from $24(39 \%)$ patients, focal motor weakness from 20 (33\%) patients, abnormal gait from 18 (30\%) patients, seizures from 17 (28) of the patients and reduced visual acuity from $16(26 \%)$ patients. Other signs and symptoms were alterations in or loss of consciousness $11(18 \%)$, abnormal co-ordination and cranial nerve palsies $10(16 \%)$ patients each, nystagmus 5 (8\%) patients, abnormal handwriting, diplopia, endocrine and growth anomalies $4(7 \%)$ patients each, abnormal tone, squint, papilledema, and optic atrophy $3(5 \%)$ patients each, abnormal speech and exophthalmia 2 (3\%) patients each while abnormal reflexes, reduced visual fields, eye pain, unequal pupils and sunset eyes had 1 (2\%) patients each.

\section{Discussion}

Pre-Diagnostic Symptomatic Interval (PSI) ranged from as low as 1

Table 1: Demographic information of the patients.

\begin{tabular}{|l|c|}
\hline & \multicolumn{1}{|c|}{ Age } \\
\hline$\leq 2$ years & \multicolumn{2}{|c|}{$7(11.5)$} \\
\hline$>2$ years & $54(88.5)$ \\
\hline \multicolumn{2}{|c|}{ Gender } \\
\hline Male & $38(62.3)$ \\
\hline Female & $23(37.7)$ \\
\hline
\end{tabular}

Table 2: Type of tumor.

\begin{tabular}{|l|c|}
\hline \multicolumn{1}{|c|}{ Type of Tumor } & Frequency $\mathbf{n ( \% )}$ \\
\hline Craniopharyngioma & $17(27.9)$ \\
\hline Medulloblastoma & $10(16.4)$ \\
\hline Pilocytic astrocytoma & $10(16.4)$ \\
\hline PNET & $6(9.8)$ \\
\hline Ependymona & $4(6.6)$ \\
\hline Brainstem glioma & $2(3.3)$ \\
\hline GBM & $2(3.3)$ \\
\hline Meningioma & $2(3.3)$ \\
\hline Thalamic glioma & $2(3.3)$ \\
\hline Choroid plexus papilloma & $1(1.6)$ \\
\hline Colloid cyst & $1(1.6)$ \\
\hline Optic glioma & $1(1.6)$ \\
\hline Pineal gland tumor & $1(1.6)$ \\
\hline SEGA & $1(1.6)$ \\
\hline Tectal glioma & $1(1.6)$ \\
\hline Total & $\mathbf{6 1 ( 1 0 0 . 0 )}$ \\
\hline
\end{tabular}

week to 3 years with a median PSI of 3 months. The mean PSI was 7.7 \pm 9.6 months.

The time to diagnosis for brain tumors is one of the longest of all childhood cancers. The study finding on PSI was comparable to the mean and median symptom interval for cohorts and case series of children with Central Nervous System (CNS) tumors published for 15 years ranging from 1.8 to 9.8 and 1 to 3 months respectively [7]. A study by Wanyoike PK, et al., [8] on children with infratentorial tumors at $\mathrm{KNH}$ showed a mean duration of symptoms of 3.7 months and the symptom median interval was 3.7 months. Other published

Table 3: Pre-diagnostic symptomatic interval.

\begin{tabular}{|c|c|}
\hline Months & Frequency n(\%) \\
\hline .2 (6 days) & $2(3.3)$ \\
\hline .5 (15 days) & $8(13.1)$ \\
\hline .7 (21 days) & $1(1.6)$ \\
\hline 1.0 & $9(14.8)$ \\
\hline 1.5 & $1(1.6)$ \\
\hline 2.0 & $9(14.8)$ \\
\hline 3.0 & $5(8.2)$ \\
\hline 4.0 & $3(4.9)$ \\
\hline 5.0 & $1(1.6)$ \\
\hline 6.0 & $1(1.6)$ \\
\hline 7.0 & $1(1.6)$ \\
\hline 8.0 & $2(3.3)$ \\
\hline 11.0 & $1(1.6)$ \\
\hline 12.0 & $4(6.6)$ \\
\hline 16.0 & $1(1.6)$ \\
\hline 18.0 & $2(3.3)$ \\
\hline 19.0 & $1(1.6)$ \\
\hline 24.0 & $6(9.8)$ \\
\hline 28.0 & $1(1.6)$ \\
\hline 36.0 & $2(3.3)$ \\
\hline Total & $61(100.0)$ \\
\hline
\end{tabular}

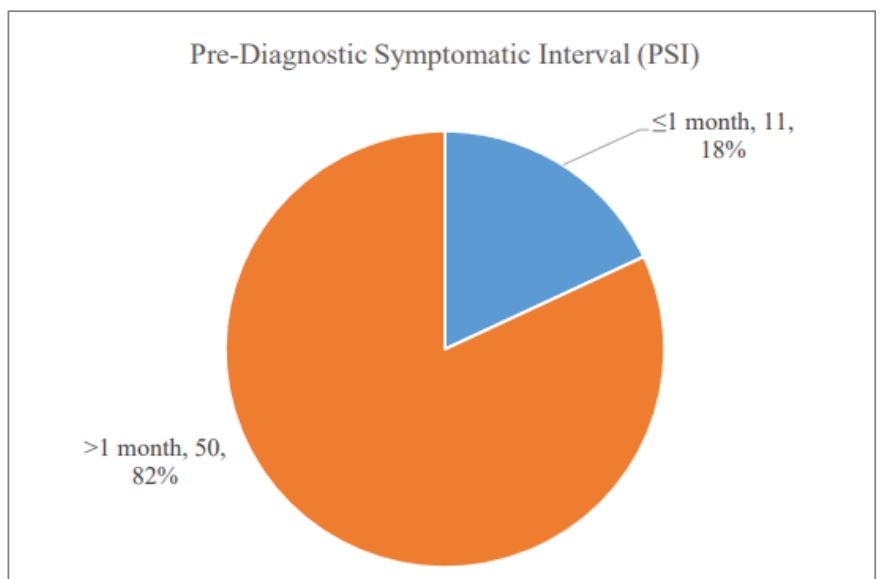

Figure 1: Pre-diagnostic symptomatic interval. 


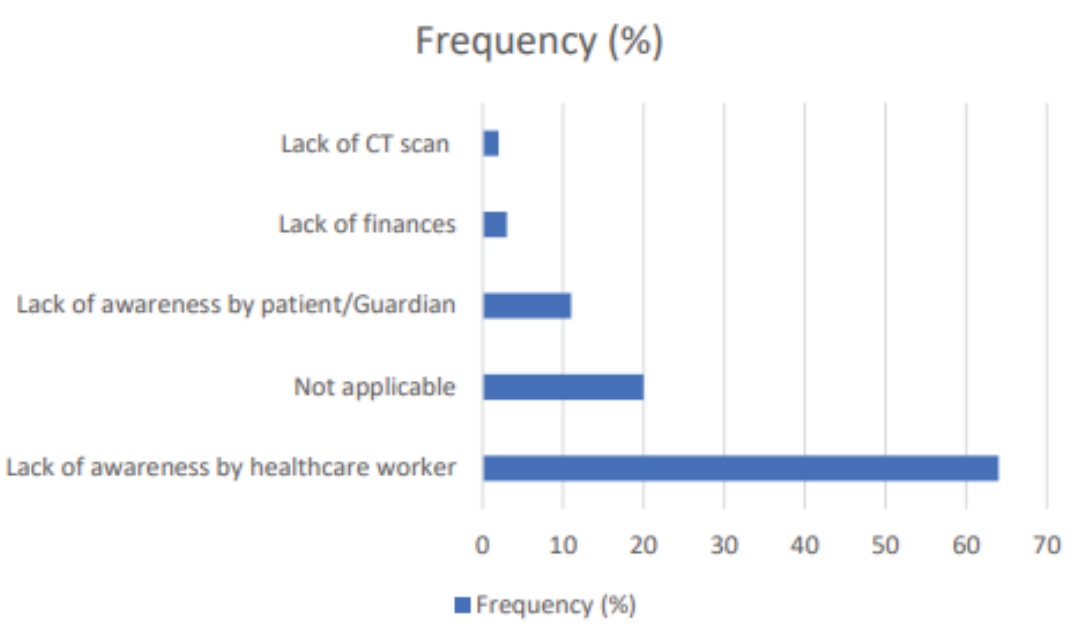

Figure 2: Factors for late diagnosis.

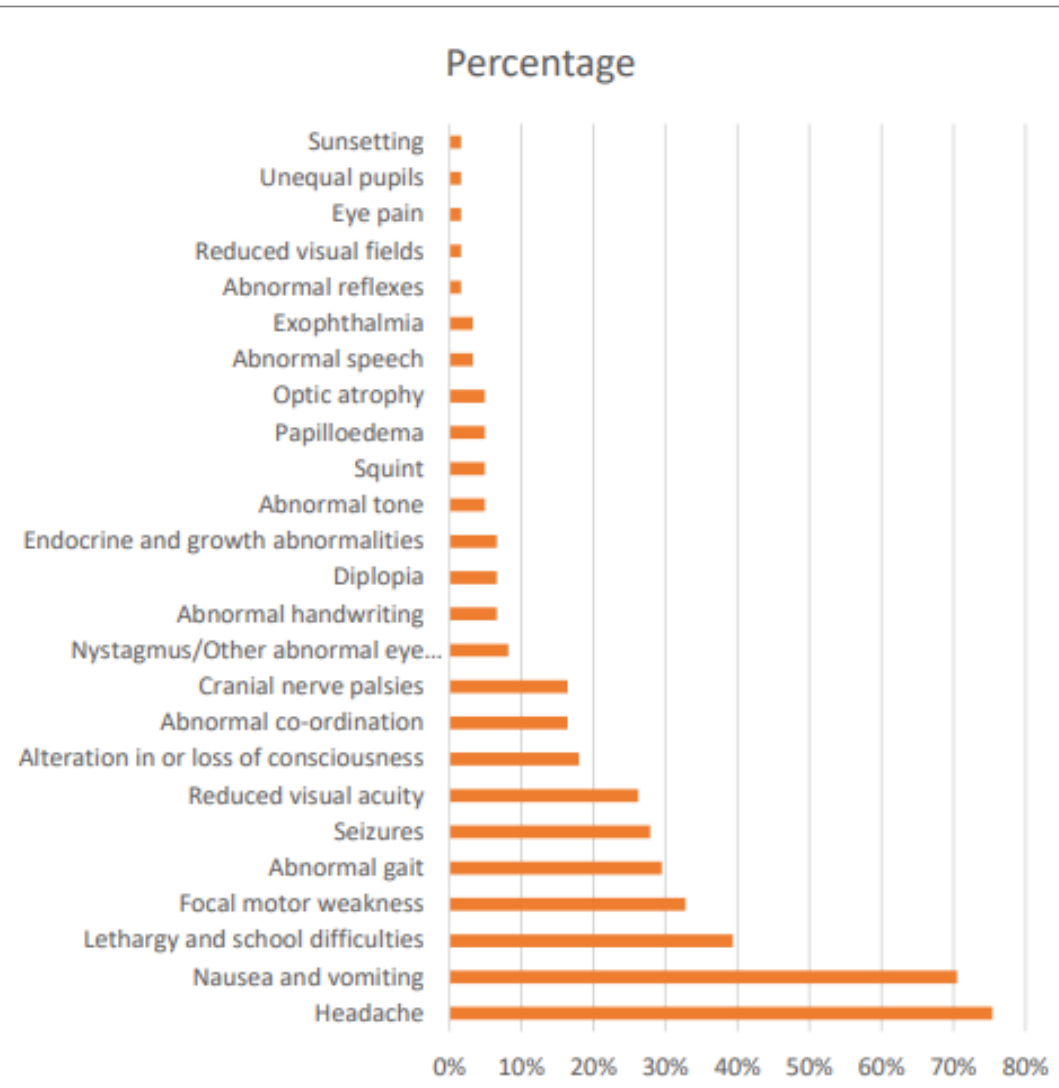

Figure 3: List of signs and symptoms.

studies recorded a median PSI range from 1.0-2.5 months [1,6,9-11]. Another study by Coven SL, et al., [12] found a mean PSI of 4.5 and a median PSI of 1.4 months. The PSI in this study was longer than the PSI recorded in the other studies.

Edith O, et al., [13] conducted a study in childhood cancers at $\mathrm{KNH}$ and found the symptom interval in $\mathrm{KNH}$ to be comparable to other developing countries but longer compared to more developed countries. In this study only, $11(18 \%)$ of the patients were diagnosed within a month of the onset of symptoms while 50(82\%) were diagnosed after a month from the onset of symptoms.

Another study found that only $33 \%$ of CBT are diagnosed within one month after the onset of symptoms [14]. This shows that at KNH the PSI was longer.

On the factors for late diagnosis, the study found the most common reason for late diagnosis was due to lack of awareness by the health 
worker 39 (64\%). The patients' records revealed that the 39 patients were presumed to suffer from other unconfirmed illnesses and were treated symptomatically without relief on several visits (from the time of first contact) before the final correct diagnosis of a brain tumor was made. The other reasons for delayed diagnosis included lack of finances, lack of awareness by the caregiver, and unavailability of imaging equipment.

In the study by Wanyoike PK, et al., [8], the reasons for late diagnosis included lack of awareness by the healthcare workers and inadequate diagnostic tools, especially in the rural areas. The high level of lack of professional awareness can be explained by the fact that there are two main neurosurgical centers in Kenya; $\mathrm{KNH}$ and Moi Teaching \& Referral Hospital (MTRH). Before referral to $\mathrm{KNH}$ neurosurgical center, most patients are seen in the lower level facilities where the majority of health workers lack awareness of childhood brain tumors. Other studies documented the main reason for delayed diagnosis as a lack of awareness by the healthcare professional $[1,2,7,9,12,15]$

The study identified 25 signs and symptoms. The varied pattern of presentation of $\mathrm{CBT}$ at $\mathrm{KNH}$ was similar to earlier studies; systematic review, and meta-analysis of studies published for 15 years in which the most common presenting symptom was a headache, followed by nausea and or vomiting with a total of 56 signs and symptoms that were recorded [5]. Another study recorded 30 signs and symptoms with a similar presentation pattern [1]. Several other studies also documented headache as the most common symptom followed by nausea and or vomiting $[6,9-11,12,16]$. The varied pattern of presentation is the main reason for the lack of awareness by the healthcare worker [12].

\section{Conclusion}

The study established the delayed diagnosis of $\mathrm{CBT}$ at $\mathrm{KNH}$ and the main reason for delayed diagnosis (lack of health worker awareness) as well as the varied pattern of presentation of $\mathrm{CBT}$ at $\mathrm{KNH}$.

\section{Recommendation}

Increasing awareness of the variable and complex symptomatology that occurs with CBT will help early tumor diagnosis and reduce the prolonged PSI. This can be done through the use of clinical guidelines.

\section{References}

1. Patel V, McNinch NL, Rush S (2019) Diagnostic delay and morbidity of central nervous system tumors in children and young adults: a pediatric hospital experience. J Neurooncol 143: 297-304.

2. Crawford J (2013) Childhood brain tumors. Pediatr Rev 34: 63-78.

3. Johnson KJ, Cullen J, Barnholtz-Sloan JS, Ostrom QT, Langer $\mathrm{CE}$, et al. (2014) Childhood brain tumor epidemiology: A brain tumor epidemiology consortium review. Cancer Epidemiol Prev Biomarkers 23: $2716-2736$.
4. Pollack IF, Agnihotri S, Broniscer A (2019) Childhood brain tumors: current management, biological insights, and future directions. J Neurosurg Pediatr 23: 261-273.

5. Wilne S, Collier J, Kennedy C, Koller K, Grundy R, et al. (2007) Presentation of childhood CNS tumors: a systematic review and meta-analysis. Lancet Oncol 8: 685-695.

6. Wilne SH, Ferris RC, Nathwani A, Kennedy CR (2006) The presenting features of brain tumors: a review of 200 cases. Arch Dis Child 91: 502-506.

7. Wilne S, Koller K, Collier J, Kennedy C, Grundy R, et al. (2010) The diagnosis of brain tumors in children: a guideline to assist healthcare professionals in the assessment of children who may have a brain tumor. Arch Dis Child 95: 534-539.

8. Wanyoike PK (2004) Posterior cranial fossa tumors in children at Kenyatta National Hospital, Nairobi. East Afr Med J 81: 258-260.

9. Arnautovic A, Billups C, Broniscer A, Gajjar A, Boop F, et al. (2015) Delayed diagnosis of childhood low-grade glioma: causes, consequences, and potential solutions. Childs Nerv Syst 31: 10671077.

10. Azad TD, Shrestha RK, Vaca S, Niyaf A, Pradhananga A, et al. (2015) Pediatric central nervous system tumors in Nepal: Retrospective analysis and literature review of low-and middle-income countries. World neurosurg 84: 1832-1837.

11. Stocco C, Pilotto C, Passone E, Nocerino A, Tosolini R, et al. (2017) Presentation and symptom interval in children with central nervous system tumors. A single-center experience. Childs Nerv Syst 33: 2109-2116.

12. Coven SL, Stanek JR, Hollingsworth E, Finlay JL (2018) Delays in diagnosis for children with newly diagnosed central nervous system tumors. Neurooncol pract 5: 227-233.

13. Edith $O$ (2013) Time intervals from symptom onset to diagnosis and treatment in childhood cancer in $\mathrm{KNH}$ and associated factors.

14. Dobrovoljac M, Hengartner H, Boltshauser E, Grotzer MA (2002) Delay in the diagnosis of pediatric brain tumours. Eur J Pediatr 161: 663-667.

15. Shay V, Fattal-Valevski A, Beni-Adani L, Constantini S (2012) Diagnostic delay of pediatric brain tumors in Israel: a retrospective risk factor analysis. Childs Nerv Syst 25: 93-100.

16. Lanphear J, Sarnaik S (2014) Presenting symptoms of pediatric brain tumors diagnosed in the emergency department. Pediatr Emerg Care 30: 77-80. 